Journal of Machine Engineering, 2020, Vol. 20, No. 2, 5-17

ISSN 1895-7595 (Print) ISSN 2391-8071 (Online)

Received: 01 March 2020 / Accepted: 02 May 2020 / Published online: 24 June 2020

on-machine measurement, thermal modelling, production metrology

Philipp DAHLEM ${ }^{1 *}$

Dominik EMONTS ${ }^{1}$

Mark P. SANDERS ${ }^{1}$

Robert H. SCHMITT ${ }^{1}$

\title{
A REVIEW ON ENABLING TECHNOLOGIES FOR RESILIENT AND TRACEABLE ON-MACHINE MEASUREMENTS
}

\begin{abstract}
On-Machine Measurements are a key factor for shorter closed quality control loops in industrial manufacturing. Especially for the production of large components, they promote the first-time-right approach, which is highly desirable, due to small quantities and steep value chains. In contrast to measurement rooms for CMMs, the production environment conditions are unregulated and impact multiple factors along the on-machine measurement metrological chain. As presented as a keynote speech at the XXXI CIRP Sponsored Conference on Supervising and Diagnostics of Machining Systems "MANUFACTURING ACTIVE IMPROVEMEN" by Professor Dr. Robert H. Schmitt, this article reviews current research and ideas regarding on-machine measurements. The authors collect necessary process data with the help of new technologies in the course of digitalization and thus propose a holistic model for systematic error compensation and measurement uncertainty prediction. For assessing the machine's volumetric accuracy under thermal loads, the authors develop a novel modelling approach, which determines transient geometric errors by abstracting structural parts as spline curve with typical deformation modes. To address the workpiece's influence on the measurement process, a data-driven framework, fusing realtime sensor-data with the virtual component, is used to model and predict transient thermo-mechanical workpiece states. For dissemination, the authors continue working on ISO standardization and, as subjects of future research, explore new paths in terms of data-driven modelling approaches, using physical abstractions coupled with machine learning and live process data.
\end{abstract}

\section{INTRODUCTION}

Reliable dimensional measurements in production environments are a major challenge in industry. Especially in the production of large components, for example in the energy sector, there is a lack of cost-effective and reliable measurement processes and systems. Due to small quantities and steep value chains in the production of large components, first-timeright production is highly desirable. Rejects or reworking cause high costs that must be

\footnotetext{
${ }^{1}$ Laboratory for Machine Tools and Production Engineering (WZL) of RWTH Aachen University, Chair of Production Metrology and Quality Management, Aachen, Germany

*E-mail: p.dahlem@wzl.rwth-aachen.de https://doi.org/10.36897/jme/122768
} 
avoided. Shifting quality inspections to the production process and thus shortening quality control loops is a promising approach, but offers implementation hurdles, regarding the often unregulated and complex environmental conditions.

With the classical coordinate measuring technique, the traceability is achieved by setting and calibrating the coordinate measuring machine utilizing traced standards. In order to be able to guarantee reliable results in the long term, all disturbing influences on the measuring process are fixed, as far as possible. The best example for this is the air-conditioned measurement room, in which coordinate measuring machines are typically operated and which minimizes temperature influences on measuring device and measurand. Additionally, the so-called virtual coordinate measuring machine (VCMM) can be used to specify the remaining residual uncertainties for specific measuring tasks [1].

The measuring process on the machine tool (On-Machine Measurements OMM) is in many respects similar to that of classic CMMs. Decisive differences are the lack of fixation of the disturbing influences and the fact that features are measured on the machine that was also used for manufacturing them. The latter creates a direct critical relation between the feature characteristics and the measurement uncertainty, which can only be resolved by the differences between the manufacturing and measuring process [2].

Manufacturing process

- Manufacturing strategy

(tool path, axes movements)

- Process forces

- Tool wear effects
Measuring process

- Measuring strategy (probing points, axes movements)

- Low contact forces during probing

- Probing almost wear-free

To overcome the environmental challenges, the following different implementation approaches can be derived.

Table 1. Solutions to environmental disturbances on machine tools [3-5]

\begin{tabular}{|l|l|}
\hline \multicolumn{2}{|c|}{ Tackling environmental challenges } \\
\hline 1. Climatization & Climatization of environment, machine and workpiece \\
\hline 2. Interim checks & $\begin{array}{l}\text { Execution of measuring tasks directly after the acceptance } \\
\text { test/interim check- suitable time-ranges depend on the individual } \\
\text { machine tool characteristics }\end{array}$ \\
\hline $\begin{array}{l}\text { 3. Definition of cceptance } \\
\text { windows }\end{array}$ & $\begin{array}{l}\text { Long-term monitoring of the temperature condition of machine } \\
\text { and workpiece, and definition of suitable temperature ranges } \\
\text { based on gained experience or a priori knowledge about the } \\
\text { thermo-elastic behaviour of machine and workpiece and feature } \\
\text { tolerances }\end{array}$ \\
\hline 4. Thermo-elastic correction & $\begin{array}{l}\text { Thermo-elastic error correction of machine and workpiece on } \\
\text { thermo-elastic model knowledge and the actual temperature } \\
\text { condition }\end{array}$ \\
\hline
\end{tabular}


In the course of digitalization and with the help of new integrated sensor technologies, the availability of process and environmental data is increasing rapidly [6-8]. Similar to the VCMM approach, this data basis can be used to generate models for optimization and task-specific uncertainty predictions for dimensional measurements on machines in production environments.

A proper implementation also requires the establishment of a holistic uncertainty model, taking machine, workpiece, environment and their mutual interaction into account [2]. The following Ishikawa diagram shows the model components which are researched by the authors and also addressed in this article.

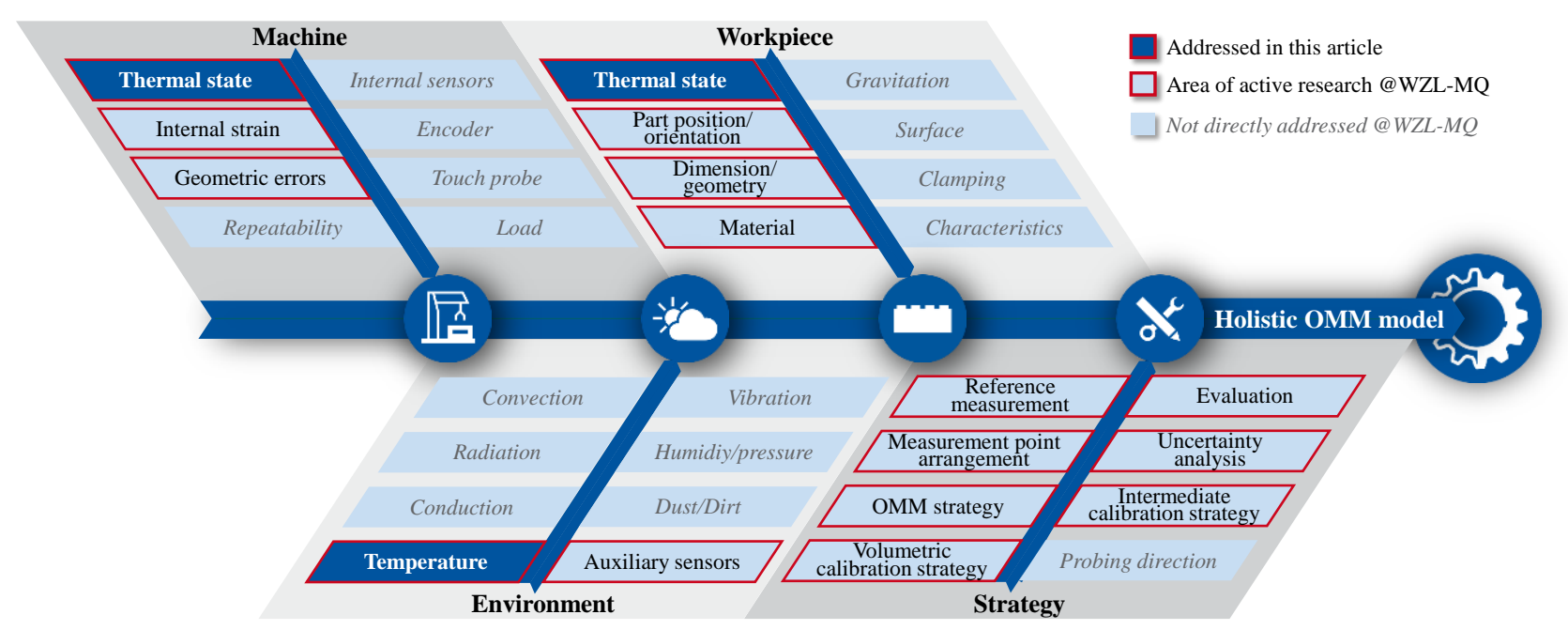

Fig. 1. Ishikawa diagram with influences on the measurement uncertainty for on-machine measurements. Blue highlighted influences are addressed in this article

In Chapter 2, the authors compare different approaches tackling disturbing influences on the machine tool, as described beforehand, and show current research activities. In Chapter 3, research predicting workpiece deformation is examined, an often disregarded field of research. Finally, the authors embed both concepts in the broader context by proposing a holistic model covering and thus compensating multiple sources of errors for on-machine measurements.

\section{MACHINE TOOL MONITORING AND MODELLING}

A machine tool's volumetric performance is subjected to multiple disturbing external and internal influences. The authors propose a hybrid machine tool error modelling approach, unifying multiple state-of-the-art and novel modelling concepts into a holistic model.

As the industry standard, following ISO 230-1:2012 [9], the so-called rigid body model (RBM) is used in all modern machine tool control systems to mitigate the effects of static structural deviation from, e.g., ideal straight guideways. Within said approach, a machine tool 
is logically comprised of several rigid bodies sequentially affixed to each other according to the kinematic chain $[10,11]$. With static compensation tables for each inter- and intra-axis error (also called geometric errors) as a data foundation, the tool's volumetric deviation is analytically computed $[12,13]$.

Acquisition of the compensation table data is performed by calibrating the machine tool using traced reference metrological systems [14]. The aforementioned action is generally time-consuming and often requires specialized equipment, thus calibrations are executed in long time intervals. [13, 15-17]

With the temporal resolution for calibrations usually in the range of multiple months, one inherent flaw in the methodology emerges: As transient errors in low-load-conditions originate mainly from (inhomogeneous) thermal expansion [18, 19], no sufficient conclusions regarding dependency of geometric errors from the thermal state can be drawn from the calibration measurements. Modern machine tools use manufacturer-provided thermal expansion coefficients to compensate for linear thermal expansion of axes. With most machines, more complex interrelationships between geometric errors and inhomogeneous thermal states are neglected. The following table gives an overview of different geometric error modelling methods, which were investigated by the authors.

Table 2. Comparison of multiple machine tool error prediction models

\begin{tabular}{|c|c|c|c|c|c|c|c|c|c|}
\hline \multicolumn{10}{|c|}{ Machine tool modelling methods } \\
\hline $\mathrm{RBM}$ & $\begin{array}{l}\text { Simple form of machine tool modelling, industrially } \\
\text { accepted and adopted }[9-12,20] \text {. }\end{array}$ & \multirow{4}{*}{ 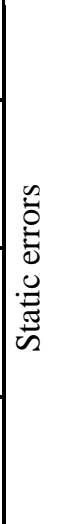 } & + & \multirow{4}{*}{ 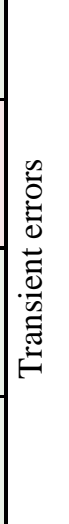 } & I & \multirow{4}{*}{ 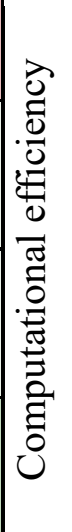 } & + & \multirow{4}{*}{ 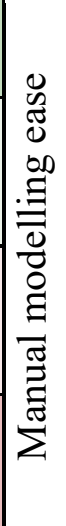 } & + \\
\hline APB & $\begin{array}{l}\text { The authors propose this novel method as an intermediary } \\
\text { step regarding machine tool construction data requirements } \\
\text { and modelling effort }\end{array}$ & & 1 & & + & & + & & + \\
\hline $\begin{array}{c}\text { Data } \\
\text { Driven }\end{array}$ & $\begin{array}{l}\text { E.g. machine learning and regression methods - Data driven } \\
\text { methods generally require vast amounts of training data for } \\
\text { modelling and are hardly transferable }[21-28]\end{array}$ & & + & & + & & 1 & & + \\
\hline $\begin{array}{c}\text { FEM } \\
(+\mathrm{CFD})\end{array}$ & $\begin{array}{l}\text { Simulating thermomechanical behavior (incl. airflows } \rightarrow \\
\text { CFD \& ambient temperatures), thus requires high computa- } \\
\text { tionnal power \& detailed modelling [29-33] }\end{array}$ & & + & & + & & i & & \\
\hline
\end{tabular}

\subsection{INTRODUCTION OF ABSTRACTED PHYSICAL BODY MODEL}

As a compromise between the drastic abstraction of the rigid body model and the modelling complexity and computational effort required with FEM analyses, the authors propose a novel modelling concept based on splines as abstracted structural machine parts.

Spline-based FEM approximation was tested by multiple researchers successfully with little deviations from FEM results [34-36]. Within the so-called Abstracted Physical Body Model (APB), introduced by the authors, structural machine elements (e.g., gantry supports, gantry beam), as well as motion-related structures (e.g., linear guideways), are abstracted as spline curves. Under (thermally) load-free condition these spline curves would be ideally straight. 
See Fig. 2 for a schematic illustration of different abstraction layers. The ensemble of interconnected splines resembles roughly the structural loop of the machine with their respective dimensions as well as the kinematic chain. With this concept, the authors try to overcome the drawbacks of FEM-based machine tool structure modelling and develop a solution, which is highly adaptable to different machine tool types even if no detail information about machine geometry and material is available.

a)

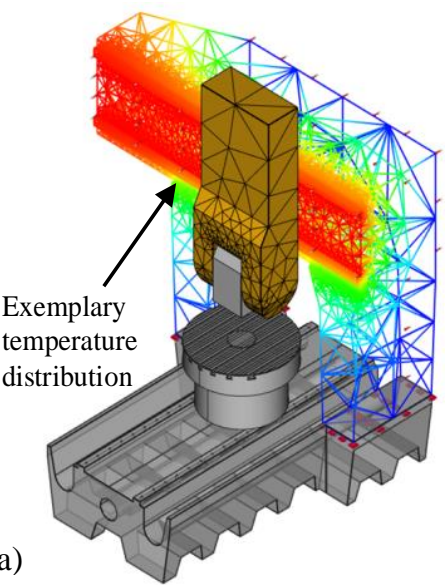

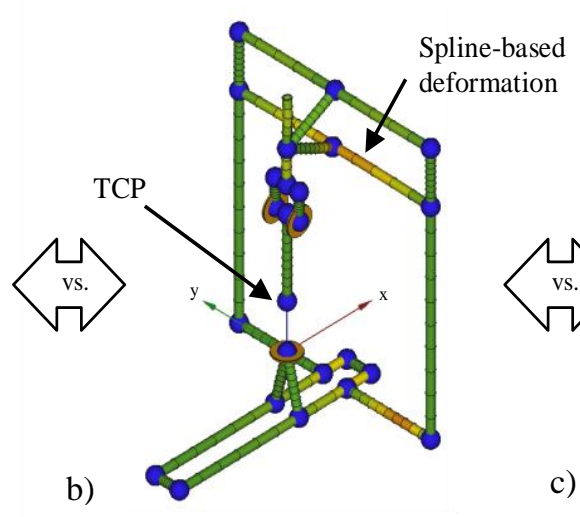

c)

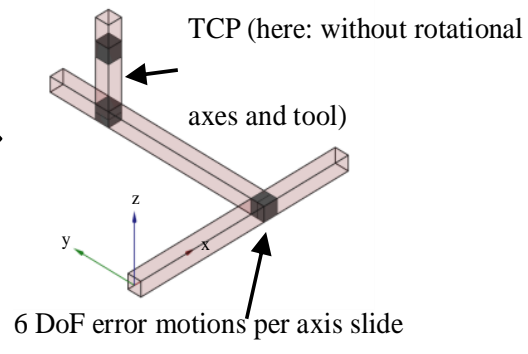

Fig. 2. Comparison of FEM-based model (a), spline-based abstracted physical body model (b) and rigid body model for linear axes and demonstrator machine rendering (c) of the same demonstrator machine DMC 75V Linear with CXFYZB-kinematic

To reduce the modelling effort at the beginning while maintaining meaningful results from the pure mathematical spline model, the authors postulate the following physically rooted assumptions and simplifications, which could be extended in the future:

- Length consistency

Structural elements mostly have oblong shapes. As such the longitudinal compression stiffness is far greater than the bending stiffnesses, thus the length of the element is constant under mechanical load and changes exclusively due to thermal expansion (see Table 3, longitudinal force/shear force).

- $\quad$ Pre-determined deformation modes

With the mathematical spline model, multiple deformation modes are possible, which must be rejected due to physical constraints.

Only certain deformations and their superpositions are allowed (see Table 3).

- Linear temperature distributions (preliminary simplification)

Temperature distributions cannot be calculated physically-based along structural parts with the simplified spline model yet. Heat sources and sinks also cannot be taken into account. Thus a linear temperature distribution between temperature constraint points ( $\rightarrow$ temperature sensors) along structural parts is assumed.

- No external forces (preliminary simplification)

With the model relying solely on mathematical constraints, there are by default no forces. Internal strain can be represented by spline deflection, but with no physical stiffness associated to splines, external forces cannot be considered. 
- No mass (preliminary simplification)

Analogous to external forces, masses of machine structure, drives, or workpiece cannot be taken into account.

Table 3. Comparison of different deformation modes with exaggerated visualization of an exemplary cantilever beam

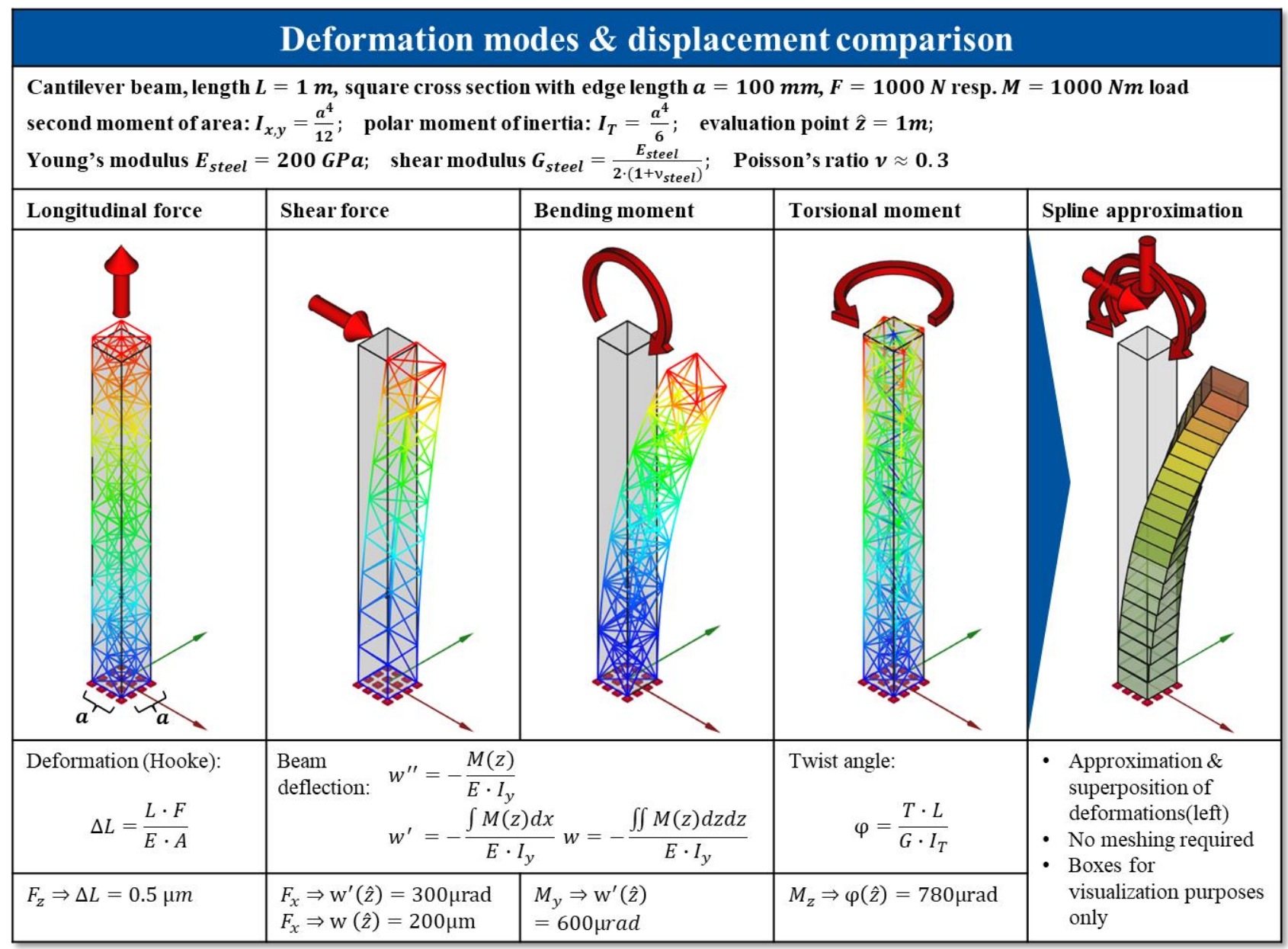

With the aforementioned assumptions, it is apparent, that the model is capable of incorporating but also relies heavily on live constraint data. Live data sources are (non-exhaustive):

- Temperature sensors

With temperature as the sole driver of lengthwise spline deformation, the model relies heavily on the availability of machine temperature information.

- Inclinometers

An Inclinometer can provide precise information regarding a point's orientation relative to the gravity vector, thus poses as constraints of a spline's slope.

- Interferometric Sensors

Interferometers measure precise position data, which constrains a point in one direction relative to another in 3D-Space. 
To deliver its full potential, the spline model is to be used as a hybrid model in superposition with the more traditional RBM approach. Static geometric errors are computed via RBM, as it is more suited for arbitrarily high resolution geometric error table data, which the Spline Model cannot provide. Only transient errors relative to the calibration (thermal) state of the machine are computed with the spline model, thus supplementing the RBM -approach.

\section{THERMAL MONITORING AND MODELLING OF THE WORKPIECE}

Besides the machine, also the influence of the workpiece can be significant to the measurement uncertainty of OMMs [1]. Main causes are gravitational and especially thermal effects. For heavy and apparently stable objects, gravitational effects are clearly detectable. They become evident not only in the form of part self-deformation but may also lead to static loads influencing the machine tool geometry during handling or clamping for manufacturing, assembly or measuring. Thermally-induced effects are manifold. They can originate from the environment, the machine or from manufacturing processes yielding thermal energy and thus changing local workpiece temperatures, which can influence the geometry significantly. Thus also the explicit modelling of the thermal characteristics of the measured workpiece is part of present research [6,37,38].

Unstable thermal conditions during geometric intermediate and final inspections lead to unsteady and inhomogeneous thermoelastic changes of the workpiece. For large components with tight tolerances, e.g. turbine components or gears, where the inner temperatures and their effects are completely unknown, thermal effects can represent a high percentage of total measurement uncertainty, for which there are only a few modelling approaches besides elaborate FEM so far [5].

The consistent heat exchange between the measurand and its environment can be traced back to the physical effects conduction, convection and radiation. Even in air-conditioned production sites, changing ambient temperatures are omnipresent, which can occur in daily, weekly or longer cycles. The influence increases proportionally with temperature differences and component size. Relevant standards specify to measure workpiece temperatures and assess the uncertainty contribution to the overall measurement uncertainty [39]. Alternatively, a sufficient long thermalisation period for temperature equalization of the workpiece is recommended [40].

Thermal influences of the measurand are still not fully considered or solely approximated very conservatively in industry-applying, if any, linear thermal expansion models or Newton's Law of cooling [5]. According to the law of thermal expansion, the extent depends on thermal load (temperature difference relative to standard temperature $\Delta T$ ) and object material properties (coefficient of thermal expansion $\alpha$ ). Assuming linear expansion, the change in linear dimension relative to the standard length $\left(\frac{\Delta L}{L}\right)$ at standard temperature can be estimated to:

$$
\frac{\Delta L}{L}=\alpha \cdot \Delta T ;[\alpha]=\frac{m}{m \cdot K},[T]=K,[L]=m
$$


The thermal expansion coefficient $\alpha$, depending on the applied material, is defined with regard to the state at a defined reference temperature (usually $20^{\circ} \mathrm{C}$ ). Stating Newton's law of cooling, the rate of heat loss of a body $\left(\frac{d Q}{d t}\right)$ is proportional to the difference in temperatures between the body and its environment $\left(T_{o b j}, T_{e n v}\right)$, the surface area $(A)$ and the heat transfer coefficient $(h)$.

$$
\frac{d Q}{d t}=-h \cdot A \cdot\left(T_{o b j}(t)-T_{e n v}\right) ; \quad[Q]=W s,[h]=\frac{W}{m^{2} \cdot K},[A]=m^{2},[T]=K
$$

According to the stated formulas, thermally induced geometric deviations, as well as thermalisation, could be determined in theory. However, the underlying assumptions of consistent single materials, constant heat transfer coefficients over the whole geometry and known homogenous temperature distributions do not reflect real-world conditions.

Along with multiple varying temperature loads, such as thermal energy from the manufacturing process, originating from machined surfaces in a non-homogenous manner accompanied by heat conduction between clamping surfaces under variable ambient temperatures, mutable thermal states and thus transient, local heat transfer coefficients over the workpiece is characteristic. Such effects are even reinforced associated with complex or asymmetric geometries with different wall thicknesses or materials, making accurate prognoses of thermal workpiece states by usage of above indicated simplified models unsatisfactory.

As a conclusion, large workpieces in the production environment can be considered as an open, transient thermodynamic system, standing in continuous interaction with its variable environment. Although it is possible to simulate and numerically solve such systems by means of commercial FEM software, the efficient application suffers from defining correct boundary conditions and very high computational effort. Thus, the research need for meaningful and efficient alternative tools arises.

\subsection{DATA-DRIVEN MODELLING OF WORKPIECE'S THERMAL STATE}

To tackle above stated challenges with respect to the current state of the art, a model -based software tool is developed at the WZL, addressing solutions for unknown inhomogeneous temperature distributions in the measured object, which is presented as follows. As depicted in Fig. 3, the basic functionality can be broken down into three major components.

\subsection{SMART TEMPERATURE SENSORS}

The authors developed smart temperature sensors, which are highly integratable to OMM scenarios promoting retrofit application. Due to their small and robust housing and wireless communication they can easily be attached on workpiece or machine surfaces, to deliver actual thermal state information, which is necessary for subsequent modelling steps. With a cable-based externally routed sensor tip, it is also possible to measure temperature 
at neuralgic but hardly accessible locations, like workpiece's cavities or machine's scale systems.

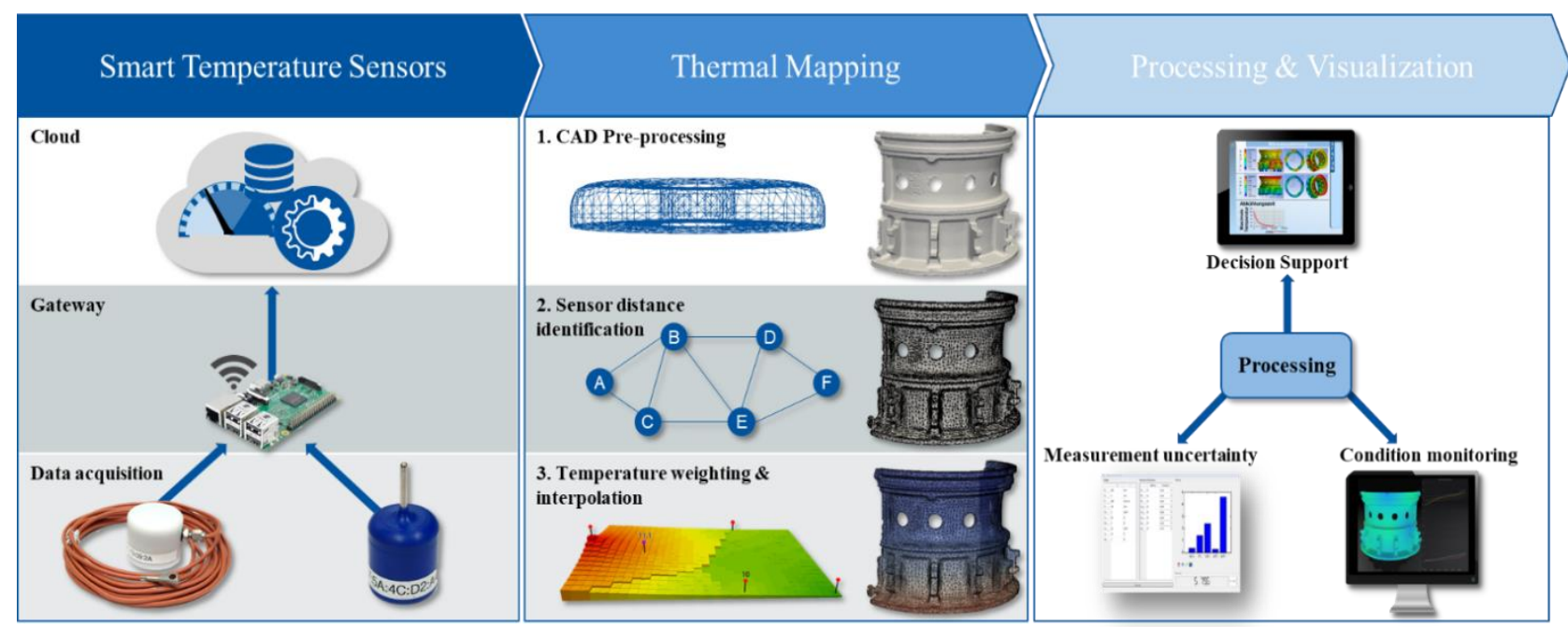

Fig. 3. Thermo-mechanical workpiece modelling framework

\subsection{THERMAL MAPPING}

To obtain an advanced understanding of the current thermal workpiece state a software is used to map and interpolate the temperature data over the whole workpiece geometry. A prerequisite for that is an existing digital representation of the nominal part geometry. The software computes all necessary steps by passing through meshing, sensor allocation, calculation of shortest node paths and interpolation (see Fig. 3). For efficient implementation, the shortest path determination is performed by a memory-optimized Dijkstra algorithm, which is referred to as uniform-cost search (UCS) in artificial intelligence [41]. Hence, thermal distribution is calculated by using grid points from sensor data. Based on a preliminary study on spatial interpolation algorithms, comparing deterministic with geostatic and data-driven methods, Kriging [42] was identified as the most powerful tool in consideration of calculation time and evaluation metrics (RMSE = root-mean-square-error, MAE = maximum-absolute-error, $\mathrm{MBE}=$ mean-bias-error). The thermal mapper output comprises colored 3D models as well as all ascertained node temperatures in a JSON file.

\subsection{PROCESSING AND VISUALIZATION}

Based on thermal mapper outputs, temperature data is captured for further utilization by the solver. Its basic framework is comparable to well established FEM methods with two distinct differences. Thermal boundary conditions are not set up in advance but coupled with real temperature measurements from workpiece's surface and from the environment. The developed solvers are tailored for individual purposes, tackling time-efficient heat transfer determination and thermal deformation calculation. An integrated optimization cycle 
ensures the reduction of thermal discrepancy $\Delta T$ between expected and measured temperatures by adapting heat transfer coefficients for every iteration step. Owing to the wellknown fundamentals of solving thermal transient problems in link with structural analyses, stating the formulation of underlying partial differential equations (PDEs) is renounced at this point. For validation, the algorithm was benchmarked against experimental data, measuring thermal deviation of two reference standards on a CMM in a climate chamber, showing overall good accordance between predicted data and physical testing results.

A web-based implementation of the presented software tool allows for both, remoted data tapping for uncertainty determination and local evaluation on an edge device as decision support for the shop floor.

\section{CONCLUSION AND FURTHER RESEARCH OUTLOOK}

Only a holistic consideration of all influencing factors along the measurement chain is capable of producing reliable measurement results and decision support systems. Along with the emerging demand for fast, reliable and close to production quality control loops, the authors take up the idea of on-machine measurements and enrich existing solutions by innovative modelling approaches for resilient and traceable measurements utilizing live process data. Within the presented framework, a possible model chain is outlined, which addresses multiple influences on the measurement process (see Fig. 4). For future traceability traced reference data for model development is a necessary requirement.

With orientation towards the CMM world, first a thorough analysis of the uncertainty components, subdividing major contributors into machine tool, workpiece, environment and strategy, is introduced (Fig. 1).

The authors introduce the abstracted physical body model for transient geometric machine error modelling which overcomes the limitations of RBM and FEM. The concept shows high approximation potential with low computational effort and high scalability to different machine kinematics. Extensive experiments are planned in the future to validate and enhance the approach towards a retrofit solution for OMM purposes.

Tackling the influence of thermo-elastic workpiece effects, a three stage compensation module, consisting of smart temperature sensors, a thermal mapper and linked solver, enabling modelling and thermal monitoring.

Present and future work within that field address machine learning (ML) enriched algorithms, emulating physical inner heat flows using pure surface sensor measurements and a priori knowledge. Solving the ill-posed problem, the algorithm relies on elaborate training, using synthetic data coming from FEM enriched with real data stemming from physical demonstrators. The focused output is a ML meta-model, which is capable of solving inverse heat transfer problems for different geometries under varying boundary conditions. Another subject of current research is the coupling of thermal photogrammetry with physical temperature sensors, enabling thermal distribution mapping with a high level of accuracy. Compared to other approaches, which rely on estimations for data between grid points, this approach is promising regarding low temperature measurement uncertainties. 
As a preliminary requirement for potential model acceptance in industry and norming organizations, a thorough measurement uncertainty analysis of all separate submodel as well as the holistic model will be executed $[43,44]$.

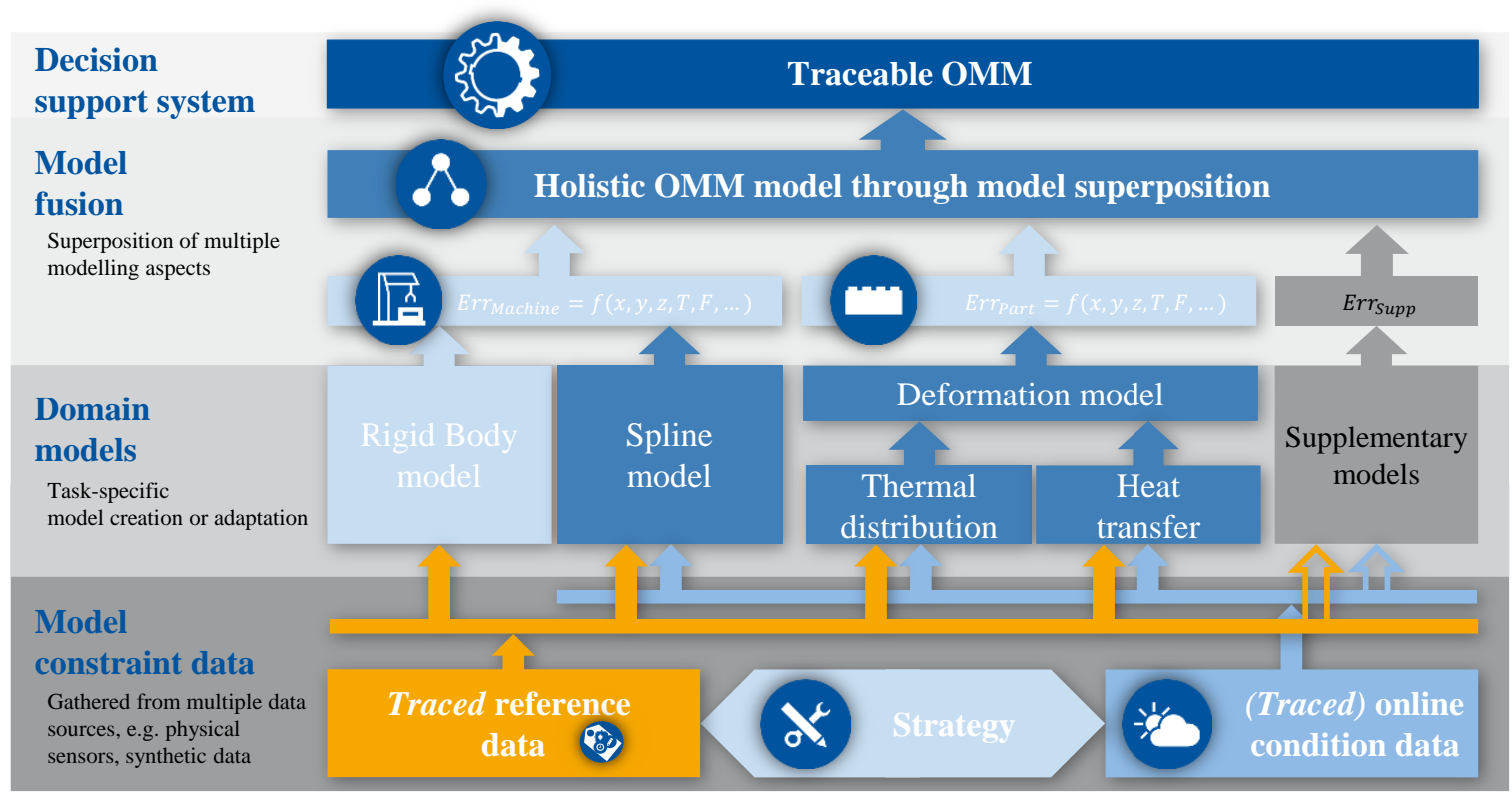

Fig. 4. Schematic abstraction of the proposed holistic modelling approach unifying multiple disturbing influences and their compensation models to achieve an optimized model accuracy and thus dependable measurement results

A following step to establish trust in these new technologies and to point out potential insufficiencies is the development of independent acceptance tests of the whole metrological chain. Together with international experts and the ISO 230 committee TC 39 SC2, the authors intend to work on acceptance test solutions and submitted the preliminary working item proposal "Acceptance tests for coordinate measurements on machine tools based an ISO 10360".

\section{ACKNOWLEDGEMENTS}

Funded by the Deutsche Forschungsgemeinschaft (DFG, German Research Foundation) under 1856/74-1 and Germany's Excellence Strategy - EXC-2023 Internet of Production - 390621612.

\section{REFERENCES}

[1] SCHMITT R.H., PETEREK M., MORSE E., KNAPP W., GALETTO M., HÄRTIG F., GOCH G., HUGHES B., FORBES A., ESTLER W.T., 2016, Advances in Large-Scale Metrology-Review and Future Trends, CIRP Annals, 65/2, 643-665.

[2] PETEREK M., 2017, Messunsicherheitsbestimmung für Geometriemessungen mit Werkzeug-maschinen, Diss., RWTH Aachen, IIF - Institut für Industriekommunikation und Fachmedien GmbH.

[3] DAHLEM P., LEHMANN N., EMONTS D., PETEREK M., SCHMITT R.H., 2019, Qualifizierung und Optimierung von Bauteilprüfprozessen auf Werkzeugmaschinen: Eignungsnachweis und Reduktion der Messabweichung mittels Modellwissen und integrierter Sensorik, VDI Wissensforum GmbH. 
[4] SCHMITT R.H., PETEREK M., 2015, Traceable Measurements on Machine Tools - Thermal Influences on Machine Tool Structure and Measurement Uncertainty, Procedia CIRP, 33, 576-580.

[5] OHLENFORST M., 2019, Model-Based Thermoelastic State Evaluation of Large Workpieces for Geometric Inspection, ISBN: 978-3-86359-752-8.

[6] OHLENFORST M., JANTZEN M., SCHMITT R.H., 2018, Verfahren und System zur in-process-Berechnung einer dreidimensionalen Temperaturverteilung, Rheinisch-Westfälische Technische Hochschule (RWTH), Aachen.

[7] UHLMANN E., LAGHMOUCHI H., GEISERT C., HOHWIELER E., 2017, Smart Wireless Sensor Network and Configuration of Algorithms for Condition Monitoring Applications, Journal of Machine Engineering, 17, 45-55.

[8] FUJISHIMA M., MORI M., NARIMATSU K., IRINO N., 2019, Utilisation of IoT and Sensing for Machine Tools, Journal of Machine Engineering, 19/1, 38-47.

[9] ISO., 2012, Test code for machine tools - Part 1: Geometric accuracy of machines operating under no-load or quasi-static conditions (230-1:2012), 3rd ed.

[10] DONMEZ M.A., BLOMQUIST D.S., HOCKEN R.J., LIU C.R., BARASH M.M., 1986, A General Methodology for Machine Tool Accuracy Enhancement by Error Compensation, Precision Engineering, 8/4, 187-196.

[11] KRENG V.B., LIU C.R., CHU C.N., 1994, A Kinematic Model for Machine Tool Accuracy Characterisation, Int. J. Adv. Manuf. Technol., 9/2, 79-86.

[12] LIN Y., SHEN Y., 2003, Modelling of Five-Axis Machine Tool Metrology Models Using the Matrix Summation Approach, Int. J. Adv. Manuf. Technol., 21/4, 243-248.

[13] SCHWENKE H., KNAPP W., HAITJEMA H., WECKENMANN A., SCHMITT R.H., DELBRESSINE F., 2008, Geometric Error Measurement and Compensation of Machines - An Update, CIRP Annals, 57/2, 660-675.

[14] JATZKOWSKI P., 2011, Ressourceneffiziente Kalibrierung von 5-Achs-Werkzeugmaschinen mit Tracking -Interferometern, Zugl., Aachen, Techn. Hochsch., Diss., 1st ed. Apprimus-Verl., Aachen.

[15] IBARAKI S., KNAPP W., 2012, Indirect Measurement of Volumetric Accuracy ffor Three-Axis and Five-Axis Machine Tools: A Review, International Journal of Automation Technology, 6/2, 110-124.

[16] SHAGLUF A., LONGSTAFF A., FLETCHER S., 2015, Derivation of a Cost Model to Aid Management of CNC Machine Tool Accuracy Maintenance, Journal of Machine Engineering, 15/2, 17-43.

[17] KWASNY W., TUREK P., JEDRZEJEWSKI J., 2011, Survey of Machine Tool Error Measuring Methods, Journal of Machine Engineering, 11/4, 7-38.

[18] BRYAN J., 1990, International Status of Thermal Error Research, CIRP Annals, 39/2, 645-656.

[19] MAYR J., JEDRZEJEWSKI J., UHLMANN E., DONMEZ M., KNAPP W., HÄRTIG F., WENDT K., MORIWAKI T., SHORE P., SCHMITT R.H., BRECHER C., WÜRZ T., WEGENER K., 2012, Thermal Issues in Machine Tools, CIRP Annals - Manufacturing Technology, 61/2, 771-791.

[20] OKAFOR A.C., ERTEKIN Y.M., 2000, Derivation of Machine Tool Error Models and Error Compensation Procedure for Three Axes Vertical Machining Center Using Rigid Body Kinematics, International Journal of Machine Tools and Manufacture, 40/8, 1199-1213.

[21] TUREK P., JEDDRZEJEWSKI J., MODRZYCKI W., 2010, Methods of Machine Tool Error Compensation, Journal of Machine Engineering, 10/4, 5-25.

[22] HOREJS O., MARES M., KOHOUT P., BARTA P., HORNYCH J., 2010, Compensation of Machine Tool Thermal Errors Based on Transfer Functions, MM SJ 2010, 01, 163-166.

[23] ZIEGERT J.C., KALlE P,. 1994, Error Compensation in Machine Tools: A Neural Network Approach. J. Intell. Manuf., 5/3, 143-151.

[24] WECK M., MCKEOWN P., BONSE R., HERBST U., 1995, Reduction and Compensation of Thermal Errors in Machine Tools, CIRP Annals, 44/2, 589-598.

[25] CHEN J.S., 1996, Neural Network-Based Modelling and Error Compensation of Thermally-Induced Spindle Errors, Int. J. Adv. Manuf. Technol., 12/4, 303-308.

[26] ZHANG X., YANG L., LOU P., JIANG X., LI Z., 2019, Thermal Error Modeling for Heavy Duty CNC Machine Tool Based on Convolution Neural Network, 2019 IEEE 3rd Information Technology, Networking, Electronic and Automation Control Conference (ITNEC), IEEE, 665-669.

[27] CHEN T.C., CHANG C.J., HUNG J.P., LEE R.M., WANG C.C., 2016, Real-Time Compensation for Thermal Errors of the Milling Machine, Applied Sciences, 6, 101, 1-13.

[28] NAUMANN C., PUTZ M., 2019, A New Multigrid Based Method for Characteristic Diagram Based Correction of Thermo-Elastic Deformations in Machine Tools, Journal of Machine Engineering, 19/4, 42-57.

[29] JEDRZEJEWSKI J., KWASNY W., KOWAL Z., WINIARSKI Z., 2014, Development of the Modelling and Numerical Simulation of the Thermal Properties of Machine Tools, Journal of Machine Engineering 14/3, 5-20.

[30] WENNEMER M., 2018, Methode zur messtechnischen Analyse und Charakterisierung volumetrischer thermoelastischer Verlagerungen von Werkzeugmaschinen, 1st ed., Apprimus Wissenschaftsverlag, Aachen. 
[31] GLAENZEL J., SURESH KUMAR T., NAUMANN C., PUTZ M., 2019, Parameterization of Environmental Influences by Automated Characteristic Diagrams for the Decoupled Fluid and Structural-Mechanical Simulations, Journal of Machine Engineering, 19/1, 98-113.

[32] GLAENZEL J., IHLENFELDT S., NAUMANN C., PUTZ M., 2018, Efficient Quantification of Free and Forced Convection via the Decoupling of Thermo-Mechanical and Thermo-Fluidic Simulations of Machine Tools, Journal of Machine Engineering, 18/2, 41-53.

[33] Da SILVA P., PENA-GONZALEZ L.E., TANABE I., TAKAHASHI S., 2018, Machine Tool Distortion Estimation Due to Environmental Thermal Fluctuations - A Focus on Heat Transfer Coefficient, Journal of Machine Engineering, 18/2, 17-30.

[34] LIU Y., SUN L., LIU Y., CEN Z., 2011, Multi-Scale B-Spline Method for 2-D Elastic Problems, Applied Mathematical Modelling, 35/8, 3685-3697.

[35] HÖLLIG K., 2003, Finite Element Methods with B-Splines, Society for Industrial and Applied Mathematics.

[36] TÖNSHOFF H.K., REHLING S., TRACHT K., 2002, An Alternative Approach to Elasto-Kinematic Modelling of Machine Tool Structures, Kulianic E. (Ed.), AMST'02 Advanced Manufacturing Systems and Technology, Proceedings of the Sixth International Conference, Springer Vienna, Vienna, 1, 215-223.

[37] OHLENFORST M., DAHLEM P., PETEREK M., SCHMITT R.H., 2016, Geometriemessungen auf Werkzeugmaschinen, wt-online - Ausgabe, 11/12, 782-786.

[38] PAVLIČEK F., MAYR J., WEIKERT S., WEGENER K., 2015, Acclimatisation Time of Precise Workpieces for Quality Inspection, Euspen's 15 ${ }^{\text {th }}$ International Conference \& Exhibition, Leuven, Belgium, 114-116.

[39] DIN EN ISO 15530-3., 2018, Geometrische Produktspezifikation - Anwendung von kalibrierten Werkstücken oder Normalen.

[40] DAWSON W., 2017, EMRP-Publishable_JRP_Report.

[41] JONES M.T., 2008, Artificial Intelligence: A Systems Approach, Computer Science Series, Jones and Bartlett Publishers.

[42] KLEIJNEN J.P.C., 2017, Regression and Kriging Metamodels with Their Experimental Designs in Simulation: A Review, European Journal of Operational Research, 256/1, 1-16.

[43] MUELLER T., HUBER M., SCHMITT R.H., 2020, Modelling Complex Measurement Processes for Measurement Uncertainty Determination, IJQRM ahead-of-print, 251.

[44] MÜLlER T., VOIGTMANN C., SCHMITT R.H., 2019, Messunsicherheitsbestimmung komplexer Prüfprozesse. ZWF, 114/3, 124-127. 